DOI: $10.17747 /$ TEDS-2020-36-39

Biruta Svagzdiene ${ }^{1}$, Edmundas Jasinskas, Arturas Simanavicius

Department of Sports and Tourism Management

Lithuanian Sports University

Sporto st.6, Kaunas, Lithuania

'biruta.svagzdiene@1su.lt

\title{
A STRATEGIC FRAMEWORK FOR A LEISURE SERVICES BUSINESS MODEL IN THE SHARING ECONOMY
}

\begin{abstract}
The sharing economy is an attractive alternative for consumers due to its economic benefits (low costs), which was seen as an important practice after the global economic crisis the growing business model presents opportunities and challenges for leisure and hospitality businesses and tourist destinations.
\end{abstract}

Keywords - framewirk; leisure, business; economy; consumer.

\section{INTRODUCTION}

The growing business model presents opportunities and challenges for leisure and hospitality businesses and tourist destinations. According to a study conducted by HR\&amp; A Advisors [1], travelers who used Airbnb spent a total of \$56 million in one year in San Francisco, California and earned income that is critical to local residents. On the other hand, the emergence of such businesses also raises the critical question of whether it creates a new market in the leisure industry or replaces the existing one (i.e. serves as a substitute for the established sector). In addition, it is also important to assess the longevity of such a business model in the light of the ever-changing business environment in hospitality. In order to provide answers to this question of the study, it is important to identify the motivational factors that encourage or hinder travelers' involvement in general consumption and to assess the potential impact of this business model in creating a new leisure and hospitality market.

The problem is: What are the challenges for the leisure industry in the sharing economy and what are the opportunities for the sharing economy when assessing the leisure sector?

The subject of the study is the impact of the sharing economy on the leisure sector.

The aim of the study is to analyze the phenomenon, opportunities and challenges of the sharing economy and to describe the impact of the sharing economy on leisure sectors

\section{SHARING THE ECONOMY AS A PHENOMENONS}

The sharing economy arose even before the urbanization period. When agriculture was the main source of income, sharing and general consumption were a simple and natural part of life, because people lived their whole lives in the same villages, so the sense of communion was incredibly strong [2].

Over time, technology has allowed people to move further out of their home and seek better livelihoods in cities. The process of urbanization has made people more independent and isolated, which has reduced the communality and sense of belonging of that time [2] It is therefore argued that exchange, trade and self-employment are not novelty, and digital technologies have simply returned to communities that have flourished in the past [3]. Global economic downturn of 2008 played a role in the creation of a modern sharing economy; when the value of costs was low, new business measures were developed. In addition, increased environmental concerns have led to success in sharing economic products and services [4]

Scientists say the sharing economy was first developed in San Francisco, USA. The USA, China, South Korea, the United Kingdom, Australia and the Netherlands are the most important regions in the sharing economy. Europe and Finland in particular are still relatively small, but its 
popularity is expected to steadily increase in the areas of accommodation, transport, finance and household services.

There have been many changes in the sharing economy over the last 15 years. To some extent, the development was initiated by the shift from materialism to the behaviour of sharing goods, when people began to perceive the pressures of the environment, accompanied by a wide range of consumerism. Nevertheless, developing digital technology has been the driving force behind the sharing of the economy [5].

From different disciplines provide different definitions and terminology of the concept of the sharing economy [6]; [7]; [8], is therefore no agreement on a universal definition that would be appropriate for all [9]. Studies that have tried to discuss the definition of a sharing economy [10]; [11]; [12]. On the one hand, [13] argue that describing the phenomenon of the sharing economy is difficult, as the practice of this leisure sector is very diverse and constantly changing, and researchers do not set specific criteria for defining the concept of this phenomenon. On the other hand, understanding the concept of sharing an economy is very important and relevant. One of the possible definitions of the allegations made by Munoz and Cohen (2016) [14] who argue that the sharing economy should be understood as a socio-economic framework allowing the exchange of goods and services between individuals and organisations aimed at increasing the efficiency and optimization of under-utilised resources in society.

The sharing economy can be understood as an economic system with five characteristics. Firstly, it is a reasonable market on whose behalf the exchange of goods and services is established [3]. Secondly, the significant impact on capital opens up new opportunities for the sharing economy, where unused assets can be converted into cash and thus fully utilised. Third,people's contacts allow capital and labour to be supplied directly from a group of individuals as a substitute for thirdcountry corporations. Finally, sharing the economy eliminates the differences between people in private and work, those with work and casual jobs [3].

Sharing economy can be divided into three main cores:

1. The access economy (initiatives sharing under-utilised assets (material resources or skills) to optimise their use);

2. Platform economy (brokering decentralised exchanges between peers through digital platforms);

3. Community economy (coordination through non-contractual, non-hierarchical or unprofitable forms of interaction (work, exchange, etc.) [15].

Example of a sharing economy business

A business model of a sharing economy where the asset is shared by two persons: the owner of the property and the asset seeker (person interested in lending the property). The claimant receives information about the assets held by analysing the online analysis and examining product descriptions displayed on the websites of service providers

Are therefore a market services platform that both parties can use and through which payments are transferred? For example, Airbnb charges $6-12 \%$ of the booking fee and 3\% from each host for each successful transaction. The owner provides information about the property on the website and answers questions about the service or product, and the searcher contacts the relevant owner of the property and asks him to reserve the dwelling for a certain period of time for the agreed fee. In addition, the sharing economy is linked to both countries, thereby creating.

Example of a customer's journey sharing economy

Keski-Heikkilä (2018) [16] carried out a study which consistently used the sharing of economic platforms in both transport and accommodation. On the basis of this research, an example of customer travel will be discussed in order to further explore the sharing economy and its possibilities in the modern world

Keski-Heikkilä (2018) has chosen a destination for personal affairs, and the reason is the desire to visit relatives living in Zagreb, Croatia. Initially, the booking process began by examining various Airbnb lists and reviewing traditional hotels and apartments. 
In Croatia, it was decided to travel with Uber, which was chosen as a mode of transport for convenience and affordable prices. In Zagreb, Uber worked extremely well on the airport, and the quality of service for each driver was good in terms of convenience and accuracy. In some cases, safety has been a concern when drivers appear to have failed to comply with speed limits. For example, few drivers have complied with traffic rules. Nevertheless, drivers were happy to communicate with passengers and were happy to make recommendations on what to see and where to go in Zagreb, which allowed the author to taste local culture.

Fig.1 Airbnb business model

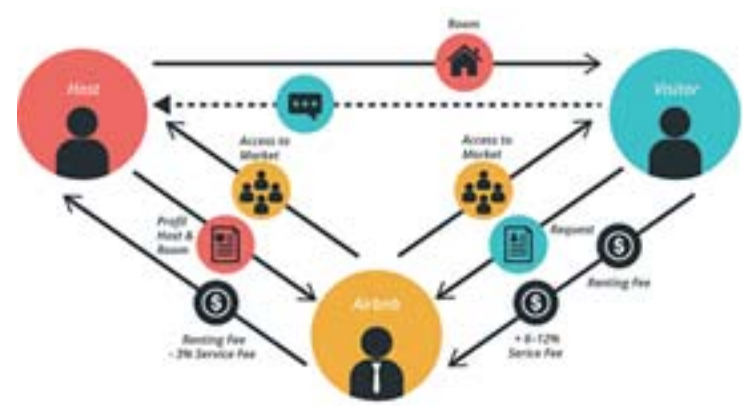

Websites are therefore a market services platform that both parties can use and through which payments are transferred. For example, Airbnb charges 6-12\% of the booking fee and 3\% from each host for each successful transaction. The owner provides information about the property on the website and answers questions about the service or product, and the searcher contacts the owner of the property concerned and asks him to reserve the dwelling for a certain period of time for the agreed fee. Addition, the sharing economy is linked to both countries, thereby building trust [17].

\section{CONCLUSIONS}

The sharing economy is constantly evolving, the main principles of the phenomenon are: more efficient use of available resources, transition from ownership to peer-sharing platforms. The sharing economy allows individuals to rent or borrow another property belonging to it. Thus, the sharing economy combines property owners and those seeking this particular asset.

The modern sharing economy is still developing, and the sharing of things is expected to be the future for many business areas. Sharing the economy offers many opportunities for Leisure and Hospitality, along with a few challenges faced by these organizations.

\section{REFERENCES}

[1] T.Geron, Will Ride-Sharing Apps Replace Car Ownership? 2012, https://www.forbes.com/sites/tomiogeron/2012/11/09/ study-airbnb-had-56-million-impact-on-san-francisco/?sh=b60324b3962a

[2] V. M. Lahti, J. Selosmaa. A fair share: Towards a new collaborative economy. Atena, 2020.

[3] A. Sundararajan. From Zipcar to the sharing economy. Harvard business review, 2013, 1(1), pp. 1-2.

[4] B. Cohen, E. Almirall, H. Chesbrough, The city as a lab: Open innovation meets the collaborative economy. California Management Review, 2016, 59(1), pp. 5-13. 
[5] K. Kelly, The Inevitable: Understanding the 12 technological forces that will shape our future. Viking. New York. 2016.

[6] R.Belk, Foreword: the sharing economy. The rise of the sharing economy: Exploring the challenges and opportunities of collaborative consumption,2018, pp. 9-12.

[7] L.Richardson, Performing the sharing economy. Geoforum, 2018, 67, pp. 121-129.

[8] I.P.Tussyadiah, Strategic self-presentation in the sharing economy: Implications for host branding. In Information and Communication Technologies in Tourism, Springer, Cham. 2016, pp. 695-708.

[9] D.Dredge \& S.Gyimóthy, The collaborative economy and tourism: Critical perspectives, questionable claims and silenced voices. Tourism recreation research, 2015, 40(3), pp. 286-302.

[10] R.Belk, Foreword: the sharing economy. The rise of the sharing economy: Exploring the challenges and opportunities of collaborative consumption, 2018, pp. 9-12.

[11] C.F. Breidbach, R.J. Brodie, Engagement platforms in the sharing economy: conceptual foundations and research directions. Journal of Service Theory and Practice, 2017, 27(4), pp. 761-777.

[12] J.Camilleri,B. Neuhofer, Value co-creation and co-destruction in the Airbnb sharing economy. Int. J. Contemp. Hospitality Manage,2017, 29(9), pp. 2322-2340.

[13] M.Herbert, I.Collin-Lachaud, Collaborative practices and consumerist habitus: An analysis of the transformative mechanisms of collaborative consumption. Recherche et Applications en Marketing (English Edition), 2017, 32(1), pp. 40-60.

[14] P.Muñoz, B.Cohen, Mapping out the sharing economy: A configurational approach to sharing business modeling. Technological Forecasting and Social Change, 2017, pp. 125, 21-37.

[15] C.J.Martin, The sharing economy: A pathway to sustainability or a nightmarish form of neoliberal capitalism?. Ecological economics, 2016, 121, pp. 149-159.

[16] E. J. Keski-Heikkilä, The challenges and possibilities of sharing economy for the travel intermediaries. 2018. https://www.theseus.fi/handle/10024/143480

[17] A. Stephany, The business of sharing: Making it in the new sharing economy. Springer, 2015 . 